\title{
SEGURANÇA DE BARRAGENS: A IMPORTÂNCIA DO MAPA DE INUNDAÇÃO NA CONSTRUÇÃO DO PLANO DE CONTINGÊNCIA PELA DEFESA CIVIL NO ESTADO DO TOCANTINS
}

Pedro Victor Dias Machado Zerbini Leão ${ }^{1}$

\section{RESUMO}

Os desastres ocorridos devido ao rompimento de barragens provocaram grandes preocupações ao governo e à população, visto que no Brasil existem milhares de barragens espalhadas por todas as regiões. A Lei Federal $\mathrm{n}^{\circ}$ 14.066, de 30 de setembro de 2020, dita as diretrizes da Política Nacional de Segurança de Barragens, que tem como instrumento o Plano de Segurança de Barragens, composto por uma série de documentos técnicos e informações, dentre eles: o Plano de Ação de Emergência. Este documento elaborado pelo empreendedor é primordial, pois tem como principal função identificar situações de emergência que possam gerar risco à população. Esses riscos são identificados pelo Mapa de Inundação, que simula o rompimento total da barragem e os possíveis danos causados pelo incidente. As informações contidas nesses documentos possibilitam ações de proteção e defesa civil, através de avisos de perigo, para procedimentos de fuga da população atingida para pontos de apoio seguros pré-estabelecidos pelo Plano de Contingência. $O$ presente trabalho analisou 3 (três) mapas de inundação de barragens do Estado do Tocantins, fazendo um comparativo das informações apresentadas com as exigências legais.

Palavras-chave: Segurança de barragens; Mapa de Inundação; Plano de Contingência; Defesa Civil.

\footnotetext{
${ }^{1}$ Major do CBMTO, Gerente de Mobilização e Minimização de Desastres da Coordenadoria Estadual de Proteção e Defesa Civil do Estado do Tocantins, Engenheiro Civil pelo CEULP/ULBRA, Especialista em Avaliações e Perícias de Engenharia pela Faculdade Ávila, Email: zerbinibm@hotmail.com.br.
} 


\title{
DAM SAFETY: THE IMPORTANCE OF THE FLOOD MAP IN THE CONSTRUCTION OF THE CONTINGENCY THROUGH PLAN FOR CIVIL DEFENSE IN THE STATE OF TOCANTINS
}

\begin{abstract}
The disasters that occurred due to collapse of dams caused great concern to the government and the population, since in Brazil there are thousands of dams spread across all regions. Federal Law no. 14,066, of September 30, 2020, dictates the guidelines of the National Dam Safety Policy, which has as its instrument the Dam Safety Plan, comprising a set of documents and technical information, including: The Plan of Emergency Action. This document prepared by the entrepreneur is essential, as its main function is to identify emergency situations that may generate risk to the population. These risks are identified by the Inundation Map, which simulates the total failure of the dam and the possible damage caused by the incident. The information contained in these documents enables protection and civil defense actions, through danger warnings, for procedures for the affected population to flee to safe support points pre-established by the Contingency Plan. The present work analyzed 3 (three) dam inundation maps in the State of Tocantins, comparing the information presented with the legal requirements.
\end{abstract}

Keywords: Dam safety; Inundation Map; Contingency plan; Civil defense. 


\section{INTRODUÇÃO}

O tema "Segurança de Barragens" vem sendo discutido constantemente pela mídia e pela população em geral; pois, além dos incidentes passados, incidentes recentes culminaram em perdas humanas, materiais e ambientais. Esse assunto tem causado pânico e incertezas às populações que habitam áreas possivelmente atingidas, em caso de rompimento dessas estruturas complexas, visto que existem, no território nacional, milhares de barragens de todos os tipos, tamanhos e alturas, que podem apresentar riscos e danos potenciais elevados. O rompimento da Barragem do Fundão, no município de Mariana-MG, no ano de 2015, considerado o maior desastre ambiental do Brasil, e o rompimento da barragem de rejeitos da Mina Córrego do Feijão, em Brumadinho-MG, no ano de 2019, considerado o maior acidente de trabalho registrado no Brasil, culminaram em danos significativos e traumatizantes, fazendo com que o governo revesse as legislações vigentes à segurança de barragens e exigisse maior fiscalização dos órgãos competentes.

O impacto da propagação da onda gerada pelo rompimento de uma barragem pode danificar edificações, rodovias, pontes; levar à perda da vida de seres humanos e a danos à flora e à fauna localizadas a jusante da barragem. Daí a necessidade de estudo prévio dos impactos possivelmente gerados para treinamento da população atingida e a sua evacuação. Quanto às barragens que armazenam rejeitos de minério, além do impacto sofrido pela onda, os rejeitos alteram as propriedades do solo e da água, o que pode levar a consequências mais catastróficas do que o rompimento de barragens de armazenamento de água (NUNES, 2019).

Logo, foi estabelecida pela Presidência da República a Lei № 14.066, de 30 de setembro de 2020, que altera a Lei oㅜ 12.334, de 20 de setembro de 2010, que estabelece a Política Nacional de Segurança de Barragens (PNSB), 
sendo essa considerada a "Lei Mãe" de segurança de barragens e atividade minerária no Brasil (BRASIL, 2010; BRASIL, 2020).

Conforme a nova PNSB, os órgãos fiscalizadores devem dar ciência aos órgãos de proteção e à defesa civil de todas as ações de fiscalização que necessitarem de adoção de medidas emergenciais de segurança para barragens. Faz-se necessário então, que o Plano de Segurança da Barragem (PSB) possua um Plano de Ação Emergencial (PAE), identificando os riscos existentes; um mapa de inundação, em que deve ser considerado o pior cenário possível (ou seja, o rompimento total da barragem), e que traga os dados técnicos das condições estruturais, instalações e dados captados por aparelhos de monitoramento (BRASIL, 2020).

Nesse sentido, as barragens podem apresentar dano potencial associado, pois sua localização e a existência de áreas habitáveis a sua jusante obriga a realização do estudo referente às zonas inundáveis, realizando uma simulação de rompimento hipotético, auxiliando no planejamento das ações de defesa civil em situações de emergência. Portanto devem ser elaborados mapas de inundação, que são documentos técnicos essenciais aos estudos de rompimento de barragem, pois apresentam a localização que a onda de cheia irá atingir e o nível de danos causados a jusante da estrutura de contenção (NUNES, 2019).

A situação emergencial das barragens é dividida em fases interna e externa. A fase interna corresponde às ações realizadas pelo empreendedor, tendo como objetivo principal as condições de operação, segurança e estabilidade. Já a fase externa compreende as ações emergenciais adotadas pela população das áreas atingidas e pelo poder público local. O Plano de Ação de Emergência (PAE) estabelece os critérios da primeira fase, através de requisitos definidos pelos órgãos fiscalizadores. Já na fase externa, as ações são definidas pelo Plano de Contingência (PLANCON), através da Defesa Civil Municipal, com o apoio da Coordenadoria Estadual de Proteção e Defesa Civil (ANA, 2016a). 
De acordo com Pedroso et al. (2018), o mapa de inundação permite o mapeamento das manchas de inundação, possibilitando o conhecimento prévio das áreas afetadas pela onda provocada pelo rompimento da barragem. Através dessas informações, é possível estabelecer procedimentos de prevenção e mitigação de danos humanos e materiais. Segundo Wahl (2004), o tempo de alerta e evacuação da população atingida, em caso do rompimento de uma barragem, pode influenciar significativamente na quantidade de perdas humanas; daí a importância da elaboração e execução dos planos de emergência, através das informações contidas nos mapas de inundação.

Nesse sentido, o presente artigo tem como objetivo responder os seguintes questionamentos: quando é exigido o mapa de inundação de uma barragem? Quais informações devem ser apresentadas nos mapas de inundação? Deve haver responsável técnico pelas informações contidas nesse documento? As informações contidas no mapa de inundação devem estar sempre atualizadas?

\section{METODOLOGIA}

O presente trabalho utilizou metodologia de pesquisa qualitativa, através de estudo teórico bibliográfico, em manuais de segurança de barragens dos órgãos fiscalizadores, cursos de segurança de barragens, da Lei ํㅡ 14.066, de 30 de setembro de 2020; da Lei oㅡ 12.608, de 10 de abril de 2012; e de dissertações e trabalhos de conclusão de cursos relacionados à Segurança de Barragens.

Foram selecionados, de forma avulsa, 3 (três) mapas de inundação de 3 (três) barragens diferentes, localizadas no Estado do Tocantins. Foi realizado estudo comparativo entre as informações técnicas apresentadas nos mapas e as exigências estabelecidas pelas legislações e manuais de segurança de barragens. Como fonte de pesquisa, foram utilizados os arquivos de Planos de 
Revista Científica do Corpo de Bombeiros Militar de Pernambuco

Artigo Publicado no Vol.07 N.20 - Edição Especial 2021 - ISSN 2359-4829

Versão on-line disponível em: http://www.revistaflammae.com

Ação de Emergência de Barragens apresentados pelos empreendedores à Coordenadoria Estadual de Proteção e Defesa Civil do Estado do Tocantins (CEPDEC) e "google" acadêmico.

\section{DESENVOLVIMENTO}

\subsection{Barragem}

De acordo com Brasil (2020), uma barragem pode ser definida como qualquer estrutura de contenção construída dentro ou fora de um curso hídrico temporário ou permanente, para fins de contenção de material líquido ou de misturas de líquidos e sólidos, contendo o barramento e demais estruturas associadas (Figura 1).

As barragens são estruturas de contenção de extrema importância para a sobrevivência dos seres vivos, pois proporcionam benefícios como a produção de energia elétrica, abastecimento de água para uso humano e/ou uso industrial, a irrigação, navegação, lazer e turismo, armazenamento de rejeitos de mineração e/ou de resíduos industriais, além de influenciar na regularização de vazões, possibilitando controle das enchentes e secas (PANIAGO, 2018).

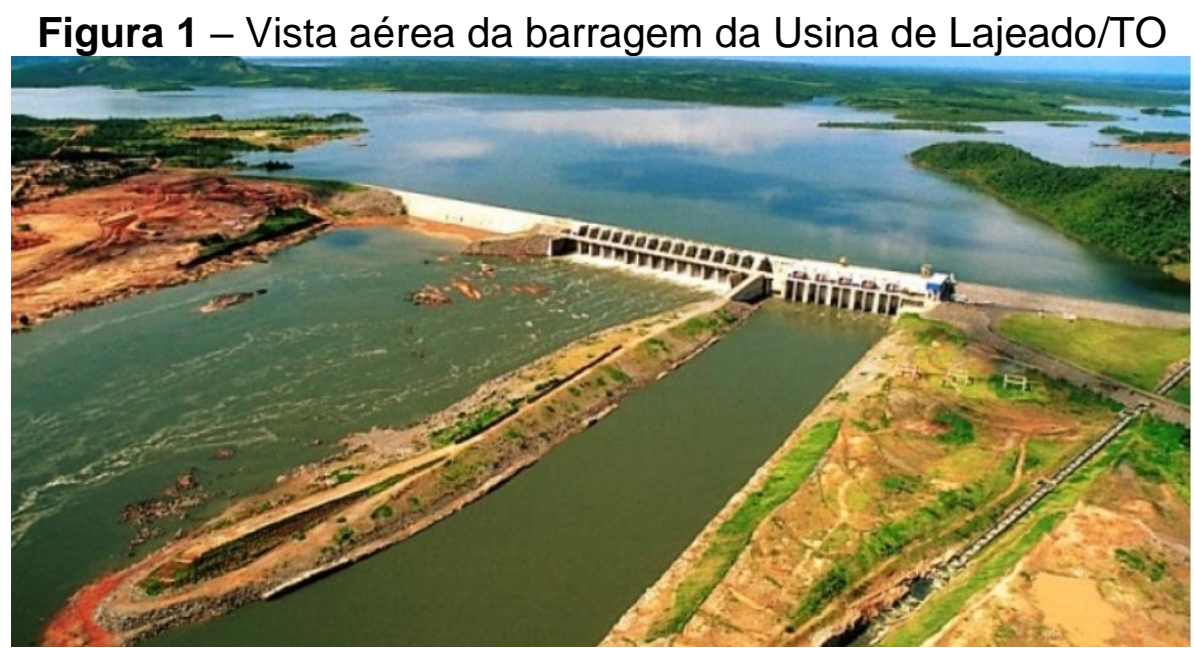

Fonte: Cunha e Pietro (2019). 
As barragens podem ser classificadas considerando diversos critérios, mas os mais utilizados são: de acordo com o tipo de material de construção (terra, enrocamento, rejeitos, concreto ou mistas) e de acordo com o comportamento estrutural (concreto por gravidade, arco e contraforte). Dentre os componentes estruturais das barragens tem-se barramento, crista, borda livre, taludes de montante e jusante, ombreiras, vertedouros e fundação. Caso algum desses componentes apresentem algum dano ou manifestação patológica, poderá haver comprometimento das condições de segurança da barragem (PINHEIRO, 2019; SCHORN; FENGLER, 2019).

\subsection{Segurança de barragens}

A Segurança de Barragens é um aspecto fundamental para todos os órgãos envolvidos, como o poder público, empreendedor e demais agentes que dão apoio técnico em todas as fases de concepção e de uso/desuso da barragem. Devem ser adotadas medidas de controle e prevenção das condições de segurança de barragens por toda sua vida útil (ANA, 2016 ab). Para a análise da segurança de uma barragem, deve-se considerar a integridade física, estrutural e operacional do maciço e seus componentes, avaliando os possíveis danos causados à vida, prejuízos à saúde, e impactos negativos às edificações e ao meio ambiente. Devem ser elaborados planos de emergência de forma a prevenir e reduzir qualquer possibilidade de acidentes ou desastres (BRASIL, 2020).

Quando as barragens são projetadas, construídas e operadas de maneira correta, elas se apresentam seguras e com pouca probabilidade de falhas. Porém, apesar de todas as precauções adotadas em suas diversas fases de concepção, sempre existirá um risco residual permanente; e, quando relacionado a avarias, pode provocar graves acidentes (CESTARY JUNIOR, 2013). Nesse sentindo, a segurança das barragens deve ser considerada em todas as fases do empreendimento, desde o planejamento a elaboração dos 
projetos, construção, até as fases de primeiro enchimento, operação e até mesmo na desativação das barragens (BRASIL, 2020).

As diretrizes a serem seguidas, quanto à segurança de barragens no Brasil, estão contidas na Lei Federal № 14.066, de 30 de setembro de 2020, que estabelece a nova Política Nacional de Segurança de Barragens (PNSB). As exigências contidas nessa lei aplicam-se a barragens com altura do maciço maior ou igual a 15 (quinze) metros, a barragens com capacidade total do reservatório maior ou igual a 3.000 .000 (três milhões) $\mathrm{m}^{3}$, a reservatórios que contenham resíduos perigosos (ABNT 10004) ou a barragens classificadas com dano potencial associado médio ou alto, e a barragens com categoria de risco alto. Essas características físicas pressupõem que são específicas de barragens que podem causar maiores danos, em caso de rompimento (BRASIL, 2020).

Para classificação das barragens quanto às suas condições de segurança, muito se confunde e provoca até caos às populações, quanto à diferença entre Dano Potencial Associado (DPA) e categoria de risco (CRI) da barragem. A DPA corresponde ao dano que pode ocorrer quanto ao rompimento total ou parcial do maciço, independente da sua probabilidade de ocorrer, avaliando-se a quantidade de perdas humanas e impactos sociais, econômicos e ambientais (BRASIL, 2020). Já o CRI classifica a barragem conforme as características técnicas, método construtivo, estado de conservação, idade da barragem e atendimento ao Plano de Segurança de Barragens, que podem influenciar na ocorrência de um acidente ou desastre. Caso uma barragem seja classificada com categoria de risco alta, essa deve passar por intervenções imediatas, pois pode estar levando risco imediato às áreas a jusante do empreendimento (BRASIL, 2020).

Essas classificações são efetuadas pelos órgãos fiscalizadores conforme as legislações específicas. Para barragens localizadas em rios de domínio da União, tem-se: conforme a Portaria no 70.389, de 17 de maio de 2017, as barragens de Mineração são fiscalizadas pela Agência Nacional de 
Mineração (ANM). Já conforme a Resolução Normativa ํo 696, de 15 dezembro de 2015, as barragens destinadas à produção de energia elétrica (hidrelétricas) são fiscalizadas pela Agência Nacional de Energia Elétrica (ANEEL), e de acordo com a Resolução n. ${ }^{2}$ 236, de 30 de janeiro de 2017, as barragens de acumulação de água são fiscalizadas pela Agência Nacional das Águas (ANA). As barragens localizadas em cursos hidros, não pertencentes à União, são fiscalizadas por órgãos ambientais estaduais e municipais.

Dentre as principais causas de ruptura de barragens, pode-se citar: galgamento, "piping" (erosão interna), deslizamento, problemas nas fundações, mau dimensionamento e problemas estruturais nos vertedouros, instabilidade no talude e outras menos frequentes (CESTARY JUNIOR, 2013).

\subsubsection{Plano de segurança de barragens (PSB)}

O PSB é um instrumento da PNSB e trata-se de um conjunto de documentos técnicos e informações que especificam as condições e ações necessárias à segurança das barragens. Dentre os principais documentos técnicos contidos no PSB, tem-se: Inspeção de Segurança Regular (ISR), Inspeção de Segurança Especial (ISE), Plano de Ação de Emergência (PAE) e Revisão Periódica de Segurança de Barragens (RPSB). O PSB é composto por 6 (seis) volumes: informações gerais, documentação técnica do empreendimento, planos e procedimentos, registros e controles, revisão periódica de segurança de barragem e volume e Plano de Ação de Emergência (BRASIL, 2020).

Toda documentação pertencente ao PSB deve ser elaborada e assinada por profissional devidamente habilitado no conselho profissional, e deve estar disponível, antes do início das operações, para todos os responsáveis pela operação, segurança (no empreendimento), para a fiscalização e SNISB. Deve ser recolhida ART/RRT de todos os documentos e, caso seja necessário, deve ser auxiliado por equipe multidisciplinar de especialistas nas diversas áreas 
que envolvam a segurança das barragens. O PSB deve ser mantido sempre atualizado e operacionalizado pelo empreendedor, até a desativação da barragem. O PSB deve estar disponível para todos os órgãos envolvidos, inclusive para a Defesa Civil, antes do início da operação da barragem. Todas as informações e documentações técnicos referentes à segurança de barragens devem ser incluídas no Sistema Nacional de Informações sobre Segurança de Barragens (SNISB), contemplando informações de qualquer incidente que coloque em questionamento a segurança da barragem (BRASIL, 2020).

\subsubsection{Plano de ação de emergência (PAE)}

Antes do início do primeiro enchimento da barragem, o empreendedor deverá elaborar, implementar e operacionalizar o Plano de Ação de emergência (PAE), que se trata de uma série de documentos formais, com indicações de possíveis situações de emergência, identificando as ações que devem ser executadas em casos de emergência, e apontando os responsáveis a serem notificados, visando diminuir os danos e perdas de vida (ANA, 2017).

O PAE é obrigatório para todas as barragens classificadas com DPA médio ou alto, ou classificada com CRI alto. Esse documento também é obrigatório para todas as barragens destinadas à acumulação de rejeitos de mineração. O Art. 12 da Lei oํ 14.066/2020 apresenta o conteúdo mínimo de documentos técnicos e informações que devem compor o PAE. Dentre a documentação principal exigida, encontra-se o Mapa de Inundação, documento técnico com informações específicas imprescindíveis para definição de estratégias necessárias para evitar ou diminuir possíveis danos relacionados ao rompimento de barragens (BRASIL, 2020).

Logo, deve ser atualizado periodicamente, o PAE deve estar disponível no "site" do empreendedor, em formato físico e digital a todos os órgãos de fiscalização, à defesa civil do município e à prefeitura constadas nas áreas 
afetadas apresentadas no mapa de inundação, SNISB e na barragem. Os órgãos de proteção e defesa civil, prefeitura municipal e a população afetada devem ser ouvidos durante a elaboração deste documento, devendo 0 empreendedor promover reuniões/simulações com as comunidades e poder público envolvido, apresentando medidas de segurança e procedimentos de evacuação em caso de emergência (BRASIL, 2020). Assim, o coordenador do PAE é o responsável por todas as ações prescritas nesse documento, devendo estar prontamente disponível nas situações de emergência, devendo emitir para as autoridades competentes uma declaração de início ou encerramento da situação de emergência (ANA, 2017).

\subsubsection{Mapa de inundação}

Compreende como mapa de inundação o documento técnico pertencente ao PAE, exigido pelo órgão fiscalizador, de responsabilidade do empreendedor, assinado pelo responsável técnico devidamente habilitado, com as devidas anotações de responsabilidades técnicas, normalmente elaborado em formato de pranchas, representadas por desenhos, plantas, mapas e legendas, tendo como conteúdo o resultado do estudo de inundação, no qual é realizada simulação do rompimento total de uma barragem (pior cenário identificado), através da utilização de "softwares", que delimita, através de coordenadas geográficas georreferenciadas, áreas potencialmente afetadas e seus cenários associados e que tem por objetivo facilitar a notificação eficiente e a evacuação de áreas afetadas por essa situação (BRASIL, 2020).

O estudo baseia-se na simulação da cheia induzida, utilizando modelos hidrodinâmicos, buscando avaliar os danos na jusante, através da determinação de zonas que vão ficar inundadas pela cheia causada pela ruptura da barragem, afetando instalações em que possam existir ocupações humanas fixas ou transitórias, infraestruturas e meio ambiente. Deve ser levada 
em consideração a metodologia da modelagem e os "softwares" utilizados, especificando os mesmos ao PAE (ANA, 2016).

No mapa de inundação, deve-se delimitar separadamente a Zona de Alto Salvamento (ZAS), que corresponde ao trecho do vale a jusante da barragem, no qual não há tempo suficiente para intervenção das autoridades competentes à situação de emergência; e a Zona de Segurança Secundária (ZSS), que corresponde ao trecho restante da jusante não definido como ZAS (BRASIL, 2020).

Deve-se adotar para ZAS a maior das seguintes distâncias para sua delimitação: a distância que corresponda ao tempo de chegada da onda de inundação igual a $30 \mathrm{~min}$ (trinta minutos) ou $10 \mathrm{~km}$ (dez quilômetros). Devem ser apresentados nos mapas de inundação seções transversais dos rios, de preferência cortando áreas com maior risco, com intervalos de pelo menos 1 $\mathrm{km}$ (para os $5 \mathrm{~km}$ iniciais a jusante da barragem). Nesses perfis, devem-se detalhar todas as informações técnicas da onda e da cheia (BALBI, 2008; ANA, 2016).

O perigo ocasionado pela onda causada pela ruptura da barragem a jusante está associado a quatro grandezas: o nível máximo de água atingido, a área submersa máxima, a taxa de subida do nível da água e as velocidades extremas do escoamento. Os mapas de inundação são importantes ferramentas na prevenção e operacionalização de estratégias de ações de prevenção de desastres. Estes mapas representam as áreas inundadas pelas cheias correspondentes ao pior cenário e informações adicionais, tais como: tempo de chegada da vazão máxima e da cota máxima de água, isolinhas e altura máxima de água. Isolinhas de velocidade máxima do escoamento. Isolinhas dos valores máximos instantâneos do produto altura de água pela velocidade de escoamento. A escala utilizada na representação das informações do mapa de inundação deverá ser adequada para a visualização dos requisitos e normalmente é elaborada com base num sistema de informação georreferenciadas (SIG). Ressalta-se que esses mapas com 
informações incertas podem originar uma eventual perda de valor econômico de áreas em função da localização delas perante o mapa de inundação (ZUFFO e GENOVEZ, 2009).

As delimitações das áreas de inundação devem ser apresentadas preferencialmente sobre mapas cartográficos em escala 1:25.000, podendo ser melhor detalhada em zonas urbanas e industriais com escalas menores (BRASIL, 2016).

Assim podemos verificar os 3 (três) principais componentes utilizados na elaboração do mapa de inundação, sendo eles: estudos hidrológicos, estudos hidráulicos e dados cartográficos. Devido à sua complexidade e aos altos custos envolvidos, é dificultosa a obtenção dos dados cartográficos. Em geral, as informações de elevação do terreno obtidas apresentam-se com baixa resolução, gerando incertezas. Essas incertezas relacionadas aos resultados obtidos podem tornar questionáveis sua aplicabilidade em projetos de engenharia (CESTARI, 2013).

As informações contidas no mapa de inundação devem possuir total veracidade e cumprir fielmente com as características existentes no cenário em risco. É importante que todas as edificações e demais infraestruturas como pontes, estradas, etc., existentes a jusante da barragem, tanto na ZAS quanto na ZSS, sejam mapeadas e identificadas com coordenadas geográficas, devendo essas informações estarem sempre atualizadas.

\subsection{Plano de contingência (PLANCON)}

Uma situação de emergência de uma barragem pode ser dividida em duas fases: fase interna e fase externa. A fase interna compreende as ações de responsabilidade do empreendedor (operação, segurança e estabilidade), estabelecidas pelo PAE. Já a fase externa corresponde aos procedimentos que devem ser adotados pela população afetada e pelo poder público local, 
contendo ações de proteção e defesa civil, sendo estabelecidas pelos Planos de Contingência Municipais (PLANCON) (ANA, 2016).

O termo PLANCON entende-se como documento que estabelece as ações de proteção e defesa civil, na tentativa de se reduzirem perdas humanas em caso de rompimento de uma barragem. O PLANCON utiliza as informações contidas no PAE para promover ações de prevenção, mitigação, preparação, resposta e recuperação, realizando um planejamento prévio, preparando a população em risco, através de ações, disponibilidade de recursos, e aferindo as responsabilidades das instituições e dos agentes públicos e privados responsáveis pela execução de ações de emergência, e apresentando contato telefônico dos agentes envolvidos (de preferência celular que seja atendido em caso de emergência). O PLANCON não dá garantia total de que não ocorrerá nenhuma vítima, porém com esse planejamento prevendo o desastre, permite aumentar as chances de preservação de vidas e integridade física das pessoas (ANA, 2016).

De acordo com Brasil (2012) e Séguin (2012), o PLANCON deve ser elaborado legalmente pela Defesa Civil Municipal, em prazo de 1 (um) ano, sendo submetido a avaliação e prestações de conta anual, por meio de audiência pública, com ampla divulgação. Compete ao município decretar situação de emergência e estado de calamidade pública, fiscalizar áreas de risco e vedar ocupações nessas áreas, identificar e mapear essas áreas, vistoriar edificações em risco, promovendo intervenção e evacuação quando necessário, dar assistência a população me situação de desastre, como abrigo, condições de higiene e segurança.

Logo, devem ser realizados, regularmente, pelo empreendedor juntamente com a defesa civil local, e representantes da população da área possivelmente afetada, exercícios práticos de simulação de situações de emergência, conforme definido pelo órgão fiscalizador, mantendo a população informada sobre áreas de riscos e ocorrência de eventos extremos, e protocolos de alerta e prevenção sobre ações emergenciais. Cabe aos Estados 
dar apoio à elaboração dos PLANCONs municipais, no levantamento das áreas de risco e divulgação dos protocolos e alertas de ações emergenciais. Compete à União apoiar Estados e municípios no mapeamento de áreas de risco, nos estudos de identificação de ameaças e demais ações relacionadas ao desastre (BRASIL, 2012).

É indispensável a integração do PAE com o PLANCON, devendo, portanto, haver perfeito entrosamento entre empreendedor, defesa civil, população afetada, agentes públicos e prefeituras, para efetiva execução do PLANCON. Após aprovação e publicidade, o PLANCON deve ser lançado do Sistema Integrado de Informações sobre Desastres (S2ID). É de responsabilidade do empreendedor estender elementos de autoproteções existentes na ZAS aos locais habitados da ZSS nos quais os órgãos de proteção e defesa civil não possam atuar, em caso de rompimento da barragem. Deve-se ocorrer cadastramento de recursos humanos, institucionais, transporte, materiais e financeiros (BRASIL, 2020).

Deve ser definido sistema de monitoramento e de alerta; e de um sistema de alarme ou comunicação efetiva; ser estabelecidas rotas de fuga e pontos seguros de encontro; ser previstas ações de socorro (ações de resgate, busca e salvamento, atendimento médico hospitalar, etc.), assistência às vítimas (abrigos, alimentação, água potável, banheiros, etc.) e restabelecimento de serviços essenciais (segurança e habitabilidade) (Figura 2). 
Revista Científica do Corpo de Bombeiros Militar de Pernambuco

Artigo Publicado no Vol.07 N.20 - Edição Especial 2021 - ISSN 2359-4829

Versão on-line disponível em: http://www.revistaflammae.com

Figura 2 - Estabelecimento de rotas de fuga e pontos de encontro.

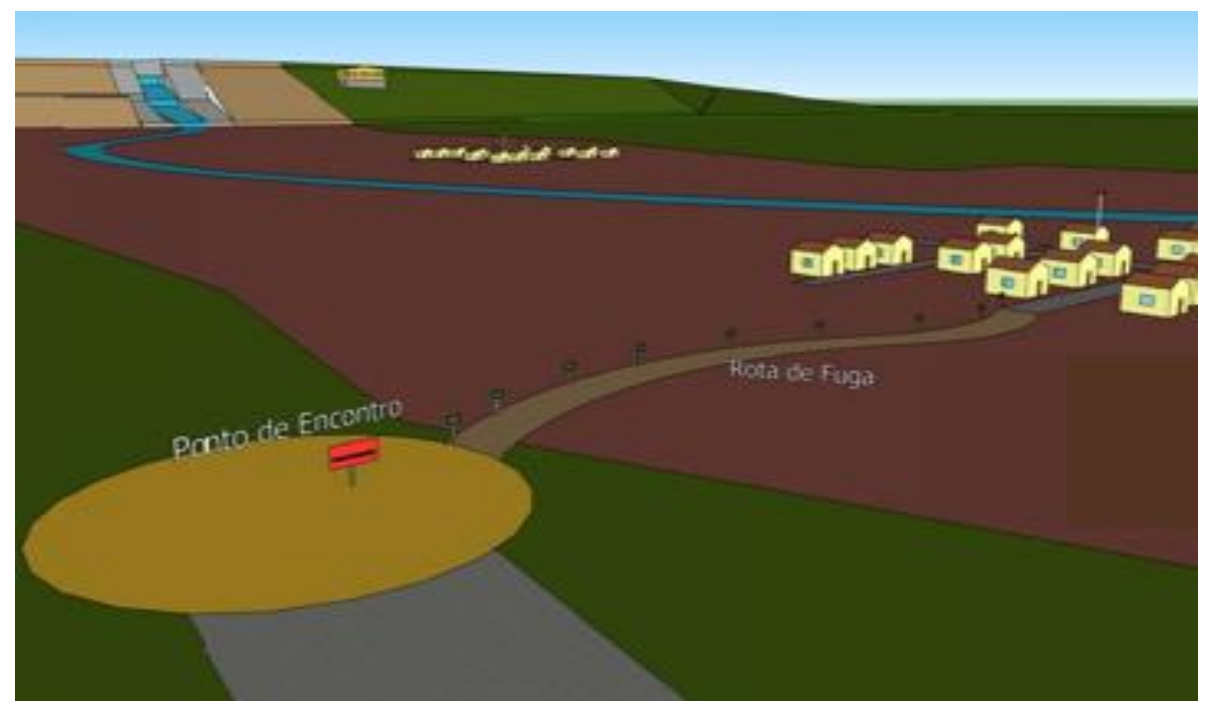

Fonte: Ana (2016).

Segundo Wahl (2004), os tempos de aviso e evacuação, em caso de alerta prévio acionado pelo resultado de um rompimento de uma barragem, é de extrema importância na diminuição de vítimas fatais. Há relatos históricos que, em procedimentos desenvolvidos, indicam que o número de pessoas que perdem suas vidas pode representar $0,02 \%$ da população situada nas zonas de risco, caso a população tenha sido alertada, 90 minutos antes da chegada da onda resultante da ruptura. Este número sobe para $50 \%$ quando o tempo de alerta diminui para 15 minutos. No estudo é apontado que a média de ocorrência de mortes devido à ruptura de barragens é 19 vezes maior quando não há um alerta ou o mesmo é deficiente.

\section{RESULTADOS E DISCUSSÕES}

Consta-se, nos arquivos da Coordenadoria Estadual de Proteção e Defesa Civil do Estado do Tocantins (CEDEC), que há exigência legal nos Planos de Ação de Emergência (PAEs) das barragens do Estado. Vale ressaltar que o mapa de inundação é um documento técnico primordial que 
compõe o PAE, e que suas informações possibilitam gerenciar as estratégias de prevenção a danos humanos em caso de rompimento de barragem.

Para esse estudo, realizou-se análise das informações contidas nos Mapas de Inundação de Barragens do Estado do Tocantins, verificando a importância dessas informações; relacionando-se as exigências especificadas nas legislações vigentes com as informações, contidas nos mapas, e apontando possíveis melhorias nesses mapas para elaboração de um eficiente Plano de Contingência.

No presente trabalho foram analisados mapas de inundação das seguintes barragens localizadas no Rio Tocantins: barragem de concreto armado de São Salvador do Tocantins, localizada entre os municípios de São Salvador e Paranã; barragem de terra de Manuel Alves, localizada entre os municípios de Dianópolis e Porto Alegre do Tocantins; e barragem de concreto armado de Luís Eduardo Magalhães, localizada entre os municípios de Lajeado e Miracema.

\subsection{Mapa de Inundação da Barragem de São Salvador do Tocantins}

No mapa de inundação da barragem de São Salvador do Tocantins (Figura 3), foi delimitada a Zona de Alto Salvamento (ZAS), considerando área de $10 \mathrm{~km}$ a jusante da UHE São Salvador, visto que essa distância corresponde à maior distância comparada com 30 minutos de onda; situação em que se considera não haver tempo para ações de defesa civil. 
Figura 3 - Mapa de inundação da barragem de São Salvador.

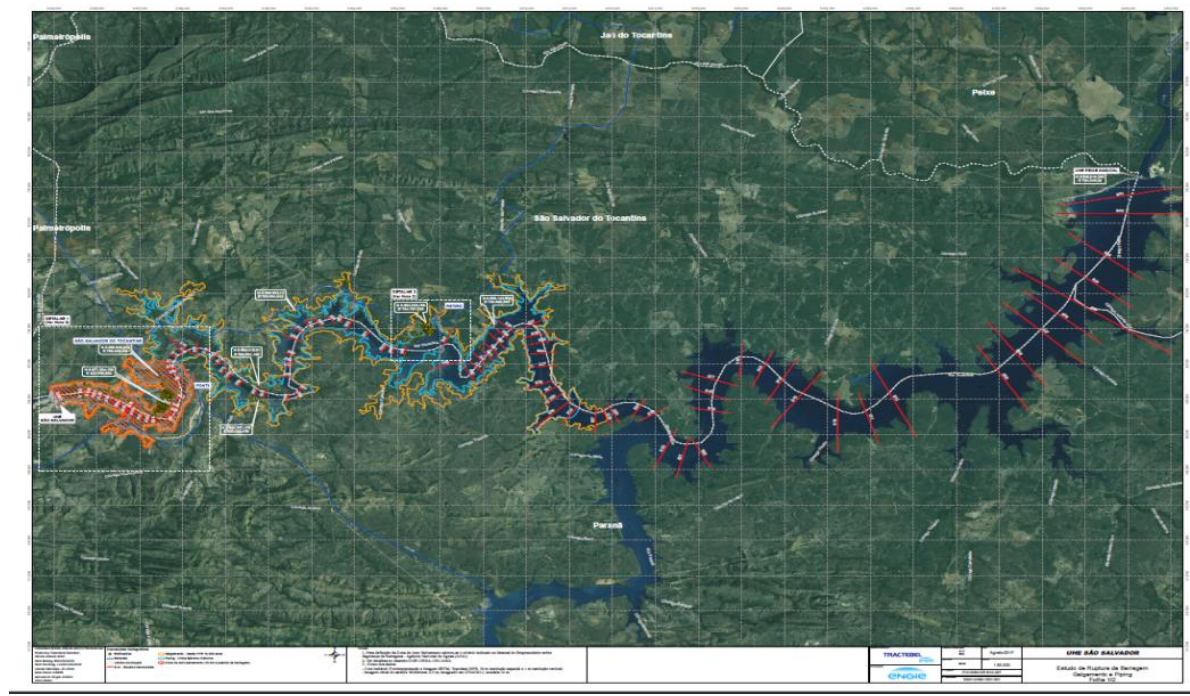

Fonte: Tractebel (2017).

As edificações situadas nas áreas inundadas pela onda de ruptura da barragem são representadas com bolas amarelas (Figura 4), nas quais são apresentadas coordenadas geográficas de grupos de edificações, porém há grupos em áreas muito extensas apresentadas apenas com uma coordenada, o que prejudica a localização de todas edificações existentes nessas áreas. Entretanto, por se tratar de um mapa em escala com coordenadas verticais e horizontais, com a utilização de um escalímetro é possível obter qualquer coordenada constante no mapa. Através de linhas coloridas são indicadas estradas, limites municipais e seções transversais. 
Revista Científica do Corpo de Bombeiros Militar de Pernambuco

Artigo Publicado no Vol.07 N.20 - Edição Especial 2021 - ISSN 2359-4829

Versão on-line disponível em: http://www.revistaflammae.com

Figura 4 - Detalhe das edificações na área de possível inundação.

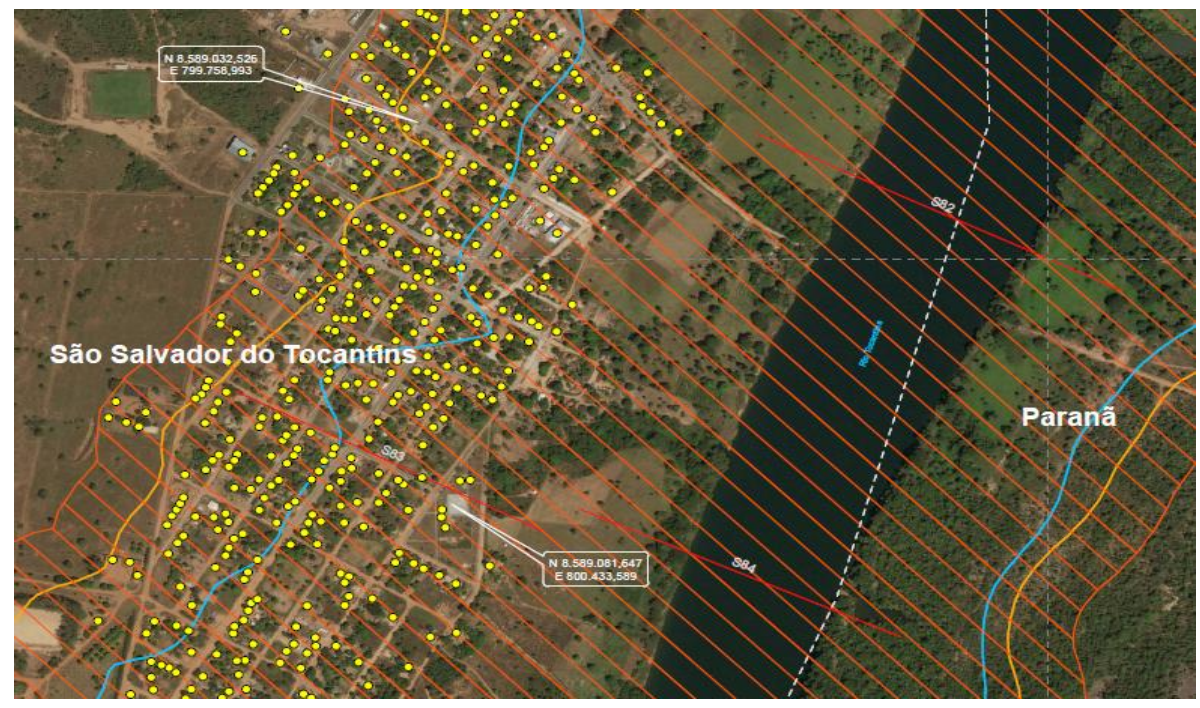

Fonte: Tractebel (2017).

No presente mapa foi delimitada a cheia proveniente do galgamento (extravasamento do material armazenado devido à incapacidade do vertedouro) da barragem, considerando vazão por período estimado de 10.000 anos e também foi delimitada cheia ocasionada por "piping" (erosão interna), considerando a cheia máxima histórica. Foi utilizada a seguinte fonte de dados: Fotointerpretação e Imagem SRTM, Topodata INPE, $30 \mathrm{~m}$ de resolução espacial e $1 \mathrm{~m}$ de resolução vertical, com imagem orbital de satélite Worldview, em 27/04/2011. A imagem de satélite, datada do ano de 2011, mostra-se bastante desatualizada, pois modificações na área da jusante podem ter ocorrido nesse vasto espaço de tempo, o que culmina em informações desatualizadas da real situação existente no local.

No mapa geral de inundação, utilizou-se a escala 1:50.000, estando em escala acima da recomendada pela ANA (2016), que é de 1:25.000, prejudicando a visualização das informações após sua plotagem; porém são apresentados detalhes importantes do mapa em escala 1:15.000 e 1:5.000, o que favorece a visualização detalhada das zonas críticas no mapa. 
Conforme Figura 4, é possível identificar todas as edificações existentes dentro das áreas de inundação, visto que se verifica a representação das edificações nas delimitações internas, a representação da linha de cheias (linha azul: cheia provocada pelo rompimento por "piping", e linha laranja: cheia provocada pelo galgamento da barragem), possibilitando a elaboração do Plano de Contingência pela Defesa Civil, visto que é possível identificar todas edificações em risco, sem informações duvidosas. Não foi observada também a existência de detalhamento das seções transversais apresentadas no mapa.

Pelas informações apresentadas no mapa de inundação não foi possível identificar o tempo de chegada da onda, profundidade e velocidade nos pontos de interesse, porém no PAE foram apresentados gráficos e tabelas que permitem acesso a essas informações. Não foram apresentadas rotas de fuga, pontos de encontro, placas de sinalização e previsão do sistema de alerta de perigo (alarme ou similar), informações extremamente necessárias à elaboração do Plano de Contingência pela Defesa Civil.

\subsection{Mapa de Inundação da Barragem Manuel Alves}

Por outro lado, o mapa de inundação da Barragem Manuel Alves (Figura 5) foi delimitada a ZAS, considerando área de $10 \mathrm{~km}$ a jusante da usina. Para melhor entendimento, dividiu-se a ZAS em três áreas de abrangência. Apesar de as coordenadas das edificações e demais infraestruturas não serem catalogadas no mapa de inundação, no PAE existem tabelas com a quantidade de edificações, coordenadas geográficas, tempo de chegada da onda e profundidade da onda. 
Revista Científica do Corpo de Bombeiros Militar de Pernambuco

Artigo Publicado no Vol.07 N.20 - Edição Especial 2021 - ISSN 2359-4829

Versão on-line disponível em: http://www.revistaflammae.com

Figura 5 - Mapa de inundação da barragem Manuel Alves.

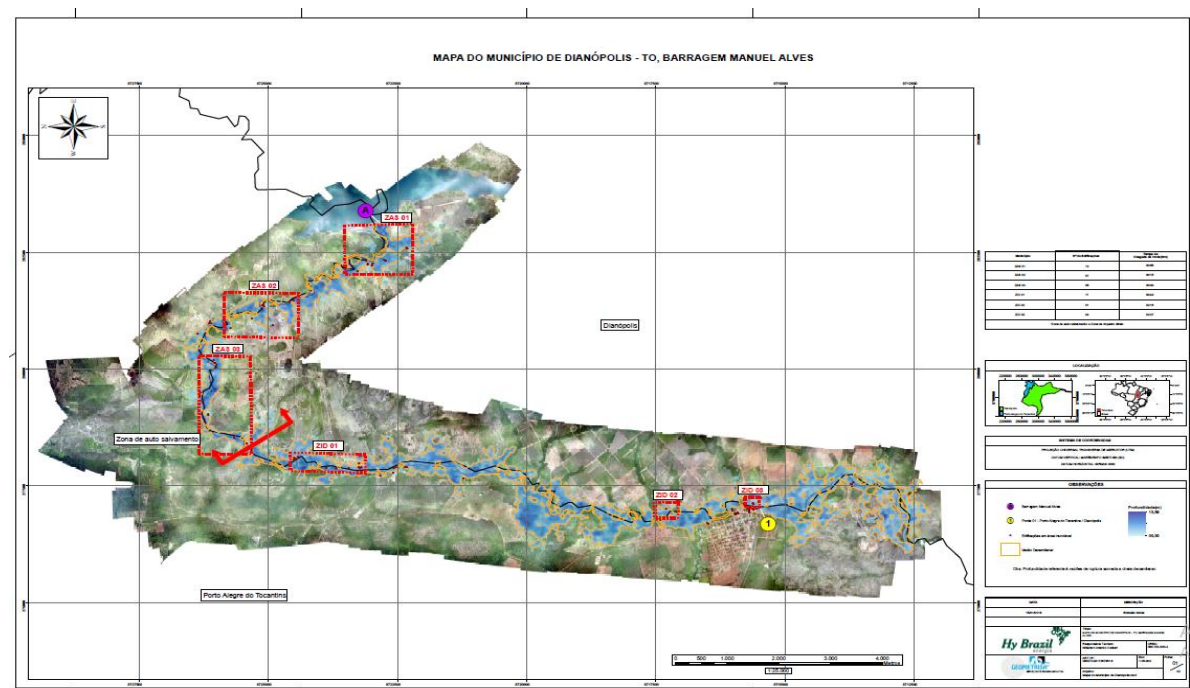

Fonte: Geometrisa Serviços de Engenharia LTDA (2019).

É possível conferir no mapa de inundação a profundidade da mancha de inundação, através de legenda de cores; vazões essas referentes à ruptura somada a cheia decamilenar. A vazão decamilenar é apresentada no mapa por linhas laranjas. Existe um quadro de legenda na prancha do mapa de inundação principal que especifica a zona de delimitação, a quantidade de edificações e o tempo de chegada da onda, facilitando a adoção de medidas necessárias à segurança da população atingida. As edificações foram representadas no mapa de inundação com círculos vermelhos.

Consta-se no mapa que a escala utilizada para o mapa geral foi de 1:25.000, porém há pranchas mais detalhadas de cada área com escalas menores. Não foram verificadas nos arquivos apresentados as seções transversais nem seu detalhamento. O mapa de inundação apresentado é datado em 15/01/2018, sendo considerado, portanto, desatualizado para trabalhos de proteção e defesa civil. Foi apresentado detalhamento de rotas de fuga e pontos de encontro, porém não há previsão de instalação do sistema de alerta de perigo (alarme ou similar). 
Revista Científica do Corpo de Bombeiros Militar de Pernambuco

Artigo Publicado no Vol.07 N.20 - Edição Especial 2021 - ISSN 2359-4829

Versão on-line disponível em: http://www.revistaflammae.com

\subsection{Mapa de Inundação da Barragem Luís Eduardo Magalhães}

No mapa de inundação da UHE Luís Eduardo Magalhães (Figura 6) foi delimitada a ZAS, considerando área de $10 \mathrm{~km}$ a jusante da usina, no mapa consta a existência de uma ponte na ZAS.

Figura 6 - Mapa de inundação da barragem Luís Eduardo Magalhães.

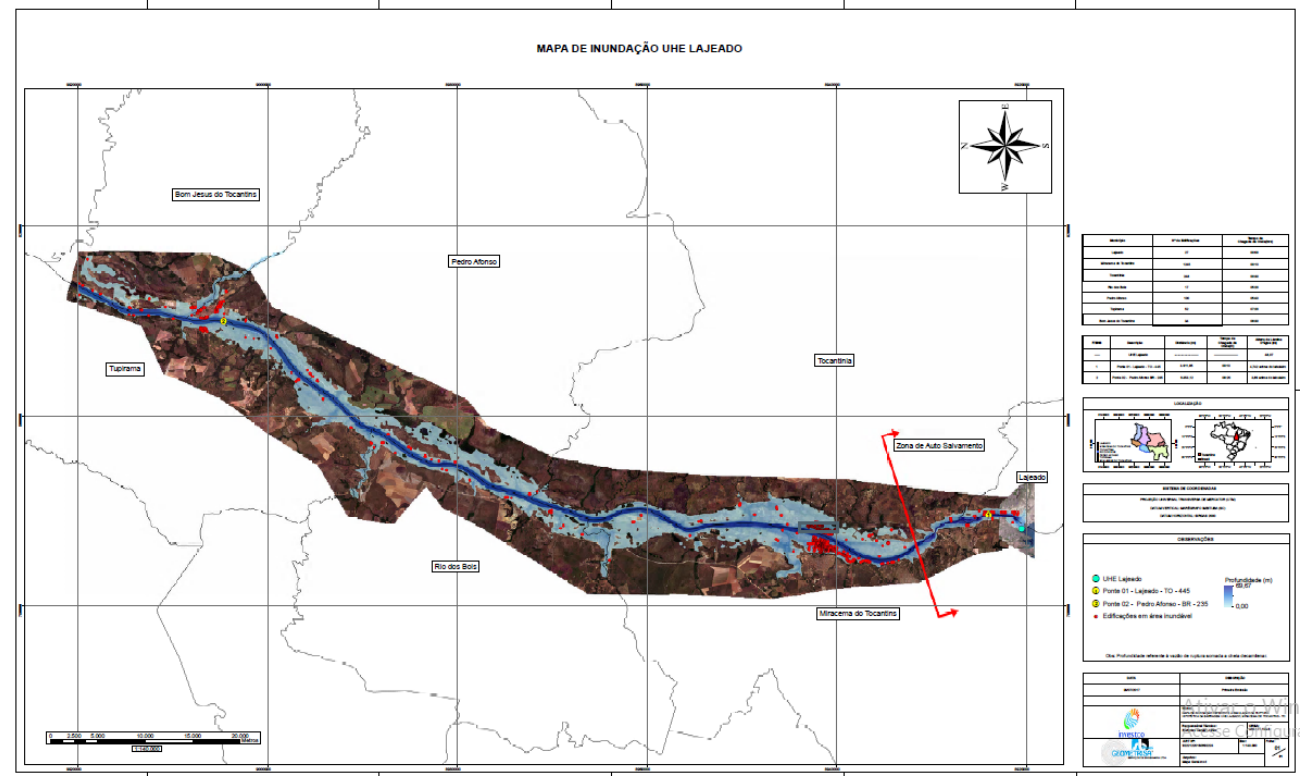

Fonte: Geometrisa Serviços de Engenharia LTDA (2019).

Através da mancha de inundação e legenda de cores, é possível verificar a profundidade da vazão formada pela onda de ruptura. Nesse mapa não foram apresentadas as linhas delimitando a vazão decamilenar. Existem dois quadros de legenda na prancha do mapa de inundação principal que especifica o município, a quantidade de edificações, tempo de chegada da onda e a distância para barragem, identificando duas pontes existentes, facilitando a adoção de medidas necessárias à segurança da população atingida. As edificações foram representadas no mapa de inundação com círculos vermelhos.

Fica constatada a existência de centenas de edificações localizadas nas áreas inundadas dos municípios de Lajeado e Miracema, cujo tempo da 
chegada da onda é de no máximo 10 minutos, o que implica em uma série de precauções a serem tomadas pelo empreendedor e pelos agentes públicos nesses municípios.

Consta-se no mapa que a escala utilizada para o mapa geral foi de 1:140.000, porém há pranchas mais detalhadas de cada área com escalas menores. Não foram verificadas nos arquivos apresentados as seções transversais nem seu detalhamento. O mapa de inundação apresentado é datado do ano de 2019, estando desatualizado para trabalhos de elaboração de plano de contingência pela defesa civil, pois o ideal é que sejam atualizadas as informações anualmente. Foram apresentados detalhamento de rotas de fuga e pontos de encontro.

Os mapas de inundação apresentados encontram-se sem assinaturas dos responsáveis técnicos nas pranchas e sem anotação de responsabilidade técnica elaborados por profissional devidamente habilitado por seu respectivo conselho. Foram apresentadas numerações de ARTs no selo dos projetos, mas não os documentos propriamente ditos. Foi apresentada ART apenas da UHE Luís Eduardo Magalhães.

\section{CONSIDERAÇÕES FINAIS}

Conclui-se que o mapa de inundação é documento primordial para que sejam desenvolvidas ações de proteção e defesa civil nas áreas afetadas pela mancha de inundação causada pela ruptura de uma barragem, pois através dele é que se obtém informações de regiões alagadas pela onda; a localização das edificações e infraestruturas existentes nessas áreas, através de coordenadas geográficas; tempo e profundidade de chegada da onda a um ponto de interesse; e delimitação separada da faixa de ZAS e ZSS e seções transversais dos trechos, com informações técnicas da onda e da cheia, devem ser apresentados nos mapas de inundação. Fazendo necessário a atualização 
dos dados, pois qualquer alteração ou dados equivocados podem gerar risco à vida de pessoas a jusante do empreendimento.

Assim, o papel da Coordenadoria Estadual de Proteção e Defesa Civil (CEPDEC) por meio de seus responsáveis técnicos, no âmbito da segurança de barragens, é dar apoio à elaboração dos Planos de Contingência municipais, no levantamento das áreas de risco e divulgação dos protocolos de emergência. Vale ressaltar que só é possível a elaboração do efetivo Plano de Contingência através de informações verídicas e precisas dos mapas de inundação.

Após análise das informações dos mapas de inundação das barragens tocantinenses, apresentados a CEPDEC, conclui-se que todos encontram-se com as informações desatualizadas devido à data dos documentos, sem devida responsabilidades técnicas e assinaturas (ARTs não foram apresentadas, somente números no selo dos projetos); há ART apenas da Barragem Luís Eduardo Magalhães; e que não há detalhamentos das seções transversais com informações técnicas da onda e da cheia. É importante que seja apresentada pelo empreendedor alternativa de aviso de perigo, seja por sistema de alarme ou similar, identificando os responsáveis por emitir tais avisos, além da locação de rotas de fuga, pontos seguros de encontro e sinalizações.

No Estado do Tocantins, a CEPDEC realizou trabalhos de criação, treinamento e fortalecimento das Defesas Civis municipais, para que fosse possível a elaboração e implantação dos Planos de Contingência de Segurança de Barragens.

\section{REFERÊNCIAS}

AGÊNCIA NACIONAL DE ÁGUAS (ANA). Manual do Empreendedor Volume I: Instruções para Apresentação do Plano de Segurança da 
\begin{tabular}{lllll}
\hline Barragem. & Brasília/DF, & 2016a. & Disponível & em:
\end{tabular} http://www2.ana.gov.br/Paginas/servicos/cadastros/Barragens/ManualEmpreen dedor .aspx. Acesso em: 05 jun. 2021.

AGÊNCIA NACIONAL DE ÁGUAS (ANA). Manual do Empreendedor Volume II: Guia de Orientação e Formulários para Inspeções de Segurança de Barragem. Brasília/DF, 2016b. Disponível em: http://www2.ana.gov.br/Paginas/servicos/cadastros/Barragens/ManualEmpreen dedo. 96 .aspx. Acesso em: 21 maio. 2021.

AGÊNCIA NACIONAL DE ÁGUAS (ANA). Ministério do Meio Ambiente e Agência Nacional de Águas. Manual de políticas e práticas de segurança de barragens para entidades fiscalizadoras / Agência Nacional de Águas. $p$. 238. Brasília: ANA, 2016. Disponível em: < https://arquivos.ana.gov.br/cadastros/barragens/ManualEmpreendedor/Manual DePoliticasEPraticasDeSegurancaDeBarragensParaEntidadesFiscalizadoras.P DF >. Acesso em 16 de outubro de 2020.

Resolução no 236, de 30 de janeiro de 2017. Estabelece a periodicidade de execução ou atualização, a qualificação dos responsáveis técnicos, o conteúdo mínimo e o nível de detalhamento do Plano de Segurança da Barragem, das Inspeções de Segurança Regular e Especial, da Revisão Periódica de Segurança de Barragem e do Plano de Ação de Emergência, conforme art. $8^{\circ}, 9^{\circ}, 10,11$ e 12 da Lei $n^{\circ} 12.334$ de 20 de setembro de 2010, que estabelece a Política Nacional de Segurança de Barragens - PNSB. Diário Oficial da União - Seção 1, p 34. Publicado em 07/02/2017. Disponível em: http://biblioteca.ana.gov.br/index.asp?codigo_sophia=65186. Acesso em: 13 jun. 2021.

BALBI, D. A. F. Metodologias para a elaboração de planos de ações emergenciais para inundações induzidas por barragens. estudo de caso: barragem de Peti - MG. 337 p. Dissertação (Mestrado em Saneamento, Meio 
Ambiente e Recursos Hídricos). Escola de Engenharia. Universidade Federal de Minas Gerais. Belo Horizonte, 2008. Disponível em: < https://repositorio.ufmg.br/handle/1843/REPA-7PUFXY >. Acesso em: 10 mai. 2021.

BRASIL. Lei $n^{\circ}$ 12.334, de 20 de setembro de 2010. Estabelece a Política Nacional de Segurança de Barragens destinadas à acumulação de água para quaisquer usos, à disposição final ou temporária de rejeitos e à acumulação de resíduos industriais, cria o Sistema Nacional de Informações sobre Segurança de Barragens e altera a redação do art. 35 da Lei n. 9.433, de 8 de janeiro de 1997, e do art. 4ํ da Lei n. 9.984, de 17 de julho de 2000. Disponível em: . Acesso em: 26 mar. 2021.

. Lei $\mathbf{n}^{\circ} \mathbf{1 4 . 0 6 6}$, de 30 de setembro de 2020. Altera a Lei $n^{\circ}$ 12.334, de 20 de setembro de 2010, que estabelece a Política Nacional de Segurança de Barragens (PNSB), a Lei oㅜ 7.797, de 10 de julho de 1989, que cria o Fundo Nacional do Meio Ambiente (FNMA), a Lei no 9.433, de 8 de janeiro de 1997, que institui a Política Nacional de Recursos Hídricos, e o Decreto-Lei no 227, de 28 de fevereiro de 1967 (Código de Mineração). Disponível em: . Acesso em: 10 maio. 2021.

. Lei no 12.608, de 10 de abril de 2012. Institui a Política Nacional de Proteção e Defesa Civil - PNPDEC; dispõe sobre o Sistema Nacional de Proteção e Defesa Civil - SINPDEC e o Conselho Nacional de Proteção e Defesa Civil - CONPDEC; autoriza a criação de sistema de informações e monitoramento de desastres; altera as Leis ํㅜ 12.340, de 1ํ de dezembro de 2010, 10.257, de 10 de julho de 2001, 6.766, de 19 de dezembro de 1979, 8.239, de 4 de outubro de 1991, e 9.394, de 20 de dezembro de 1996; e dá outras providências. Diário Oficial da União 2012; 11 abr. 
CESTARI, E. J. Estudo de propagação de ondas em planície de inundação para elaboração de plano de ação emergencial de barragens: UHE Três Irmãos estudo de caso. Dissertação (mestrado) - Universidade Estadual Paulista Júlio de Mesquita Filho, faculdade de Engenharia de Ilha Solteira, p. 189, 2013. Disponível em: <http://hdl.handle.net/11449/111148>

CUNHA, A.; PIETRO, M. D. Investco desmente Fake News sobre hidrelétrica de Lajeado e garante que barragem é segura. Conexão Tocantins, Palmas, 13 de fevereiro de 2019. Disponível em: https://conexaoto.com.br/2019/02/13/investco-desmente-fake-news-sobrehidreletrica-de-lajeado-e-garante-que-barragem-e-segura

GEOMETRISA. A sua primeira opção em segurança de barragens. (2019). Disponivel em: http://geometrisa.com.br/\#. Acesso em: 14 de setembro de 2021.

NUNES, T. A. Estudo de zonas de risco de inundação em decorrência de rompimento de barragem - estudo de caso: represa do Iraí - PR. Trabalho de conclusão de curso (Graduação em Engenharia Civil). Faculdade de Engenharia Civil da Universidade Federal do Paraná. Pontal do Paraná, p.66. 2019. Acesso

em: https://www.acervodigital.ufpr.br/bitstream/handle/1884/66147/TCCThaisCorrigi doFinalCompleto.pdf?sequence $=1$ \&isAllowed $=y$

PANIAGO, L. Principais usos das barragens e suas aplicabilidades. Instituto Minere, Belo Horizonte, 26 de outubro de 2018. Disponível em: $<$ https://institutominere.com.br/blog/principais-usos-das-barragens-e-suasaplicabilidades>. Acesso em 06 de maio de 2021. 
PEDROSO, A.; PALMA, G. P. O.; OLIVEIRA, J. A. S. GARCIA, C. S.; CUNHA, L. M. Análise da influência de dados cartográficos na determinação de manchas de inundação no rompimento hipotético de uma barragem. In: Simpósio de recursos hídricos do Nordeste, XIV, Maceió- Alagoas. 2018. Disponível em: https://eventos.abrh.org.br/xivsrhne/apresentacoes/10797.pdf

PINHEIRO, I. Barragens na Engenharia: Tipos e Patologias. Disponível em: https://www.inovacivil.com.br/barragens/ , 2019.

SCHORN, Y. A. G.; FENGLER, R. Z. Barragens de Rejeitos de Minérios e as Condicionantes Geotécnicas Envolvidas. Revista GEDECON-Gestão e Desenvolvimento em Contexto, v. 7, n. 2, p. 34-40, 2019.

SÉGUIN, E. A lei de defesa civil: algumas considerações. Revista Interdisciplinar do Direito - Faculdade de Direito de Valença, [S.I.], v. 9, n. 1, p. 207-230, dez. 2012. ISSN 2447-4290. Disponível em: $<$ http://revistas.faa.edu.br/index.php/FDV/article/view/514>. Acesso em: 19 jul. 2021.

TRACTEBEL, E. E.; Hinicio, H. Study on Early Business Cases for H2 in Energy Storage and More Broadly Power To H2 Applications. EU Comm, v. 228, 2017.

WAHL, T. L. Uncertainty of predictions of embankment dam breach parameters. Journal of hydraulic engineering, v. 130, n. 5, p. 389-397, 2004.

ZUFFO, M. S. R.; GENOVEZ, A. I. B. Dam Safety Legislation: a focus on the different approaches. In: Advances in Water Resources and Hydraulic Engineering. Springer, Berlin, Heidelberg, 2009. p. 1854-1859. 